\title{
Development and evaluation of a Nutrition Transition-FFQ for adolescents in South India
}

\author{
Nida I Shaikh ${ }^{1, *}$, Jennifer K Frediani ${ }^{2}$, Usha Ramakrishnan ${ }^{1,3}$, Shailaja S Patil ${ }^{4}$, \\ Kathryn M Yount ${ }^{3,5}$, Reynaldo Martorell ${ }^{1,3}$, KM Venkat Narayan ${ }^{1,3}$ and \\ Solveig A Cunningham ${ }^{1,3,5}$ \\ 'Doctoral Program in Nutrition and Health Sciences, Laney Graduate School, Emory University, 1518 Clifton Road \\ NE, 7040-J, Atlanta, GA 30322, USA: ${ }^{2}$ Emory College, Center for the Study of Human Health, Emory University, \\ Atlanta, GA, USA: ${ }^{3}$ Hubert Department of Global Health, Emory University, Atlanta, GA, USA: ${ }^{4}$ Department of \\ Community Medicine, Shri. B.M. Patil Medical College, BLDE University, Vijayapura, India: ${ }^{5}$ Department of \\ Sociology, Emory University, Atlanta, GA, USA
}

Submitted 13 April 2016: Final revision received 8 0ctober 2016: Accepted 25 October 2016: First published online 10 January 2017

\begin{abstract}
Objective: To develop and evaluate a Nutrition Transition-FFQ (NT-FFQ) to measure nutrition transition among adolescents in South India.

Design: We developed an interviewer-administered NT-FFQ comprising a 125-item semi-quantitative FFQ and a twenty-seven-item eating behaviour survey. The reproducibility and validity of the NT-FFQ were assessed using Spearman correlations, intra-class correlation coefficients (ICC), and levels of agreement using Bland-Altman and cross-classification over 2 months (NT-FFQ1 and NT-FFQ2). Validity of foods was evaluated against three 24-h dietary recalls (24-HR). Face validity of eating behaviours was evaluated through semi-structured cognitive interviews. The reproducibility of eating behaviours was assessed using weighted kappa $\left(\kappa_{\mathrm{w}}\right)$ and cross-classification analyses.

Setting: Vijayapura, India.

Subjects: A representative sample of 198 adolescents aged 14-18 years.

Results: Reproducibility of NT-FFQ: Spearman correlations ranged from 0.33 (pulses) to 0.80 (red meat) and ICC from 0.05 (fruits) to 1.00 (tea). On average, concordance (agreement) was $60 \%$ and discordance was $7 \%$ for food groups. For eating behaviours, $\kappa_{\mathrm{w}}$ ranged from 0.24 (eating snacks while watching television) to 0.67 (eating lunch at home) with a mean of 0.40 . Validity of NT-FFQ: Spearman correlations ranged from $0 \cdot 11$ (fried traditional foods) to 0.70 (tea) and ICC ranged from 0.02 (healthy global foods) to 1.00 (grains). The concordance and discordance were $48 \%$ and $8 \%$, respectively. Bland-Altman plots showed acceptable agreement between NT-FFQ2 and 24-HR. The eating behaviours had acceptable face validity.

Conclusions: The NT-FFQ has good reproducibility and acceptable validity for food intake and eating behaviours. The NT-FFQ can quantify the nutrition transition among Indian adolescents.
\end{abstract}

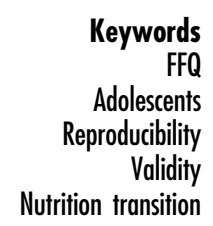

Globalization, urbanization and economic growth in low- and middle-income countries including India are associated with the nutrition transition - the phenomenon hypothesized to encompass shifts in dietary patterns, eating behaviours and physical activity patterns ${ }^{(1,2)}$. Concomitant with the nutrition transition, obesity and other chronic diseases have emerged among adults, adolescents and children across social strata ${ }^{(3-6)}$. Validated dietary assessment instruments could measure the extent of nutrition transition through food intake and eating behaviours associated with it. Typical dietary assessment instruments such as FFQ and $24 \mathrm{~h}$ dietary recalls (24-HR) have been used to determine food consumption and nutritional status ${ }^{(7)}$. However, there is no FFQ developed to assess the nutrition transition. In addition, with the availability of and accessibility to global or non-local foods and beverages through globalizing food markets, the diets of individuals are likely to include both global and traditional items. Studies have reported behaviours that may be part of the nutrition transition, including eating outside the 
home $^{(8)}$ and watching television while eating meals ${ }^{(9)}$. Although studies indicate that these trends may be becoming more common, especially in adolescents aged $10-19$ years $^{(8)}$, currently there is no dietary instrument that quantifies these and other nutrition transition-related food consumption and eating behaviours.

At the forefront of social change and global trends ${ }^{(10)}$, adolescents in low- and middle-income countries may be experiencing nutrition transition-related shifts in food consumption and eating behaviours. In India, adolescents comprise one-fifth of the population $(\sim 243 \text { million })^{(11)}$, of which $37 \%$ are underweight and $5 \%$ are overweight or obese $^{(12)}$. A few FFQ have been used in epidemiological studies among adolescents in India ${ }^{(13-15)}$, but the validity and reproducibility of these FFQ have not been documented. The 24-HR method has been used by the National Nutrition Monitoring Bureau of India to assess periodically the nutritional status of adolescents in selected states ${ }^{(16)}$. Unlike FFQ, 24-HR are not representative of long-term food intake ${ }^{(17)}$ and are also not as practical and costeffective ${ }^{(18,19)}$. The lack of validated dietary instruments limits the information known about the nature of dietary changes that may be occurring among adolescents in India. Assessing the dietary changes that are part of the nutrition transition requires validated dietary instruments to measure long-term trends and changes, not only in food intake but also in eating behaviours.

The objective of the present study was to develop and evaluate the validity and reproducibility of a Nutrition Transition-FFQ (NT-FFQ) to measure nutrition transitionrelated food consumption and eating behaviours among adolescents aged 14-18 years in South India.

\section{Methods}

\section{Setting}

The study was carried out from June 2013 to January 2014 in Vijayapura in Karnataka, India. Vijayapura is a midsized city (population 350 000) located in Karnataka in a district which is categorized as economically underdeveloped but is urbanizing as a result of the major economic growth of its small-scale industries, including agriculture, and its large-scale industries, including sugar and textiles ${ }^{(20)}$. Vijayapura serves as a prototype mid-sized Indian city that is underdeveloped but undergoing urbanization and experiencing exposure to non-local and global trends ${ }^{(21)}$. The Institutional Review Board at Emory University, Atlanta, GA, USA and the Institutional Ethical Committee at BLDE University, Vijayapura, India approved the study.

\section{Interviewer recruitment and training}

Twelve field interviewers proficient in English and the local language, Kannada, were recruited and trained to administer the NT-FFQ and 24-HR and to obtain the written informed consent from the adolescents' caregivers and assent from participants. Mock interview sessions were conducted in Kannada prior to field testing of the instrument to ensure that interviewers were familiar with food items and to ensure uniformity in the data collection techniques.

\section{Development of the NT-FFQ}

\section{Qualitative fieldwork to identify food items}

The NT-FFQ was developed using a sequenced mixedmethods approach including formative qualitative fieldwork. The NT-FFQ comprised a 125 -item semi-quantitative FFQ section that measured food consumption over a month and a twenty-seven-item eating behaviour section that quantified eating behaviours over a week. The food items listed in the NT-FFQ were built using two methods: (i) identification of food items, including the commonly consumed local, regional and global foods, from our previous 24-HR from adolescents; (ii) and written freelists of the most commonly available foods and beverages in stores identified by a purposive sample of adolescents ( $n$ 26) aged 14-18 years. Freelisting, an elicitation technique, involves asking individuals to list all the items that they can think of for a given cultural domain ${ }^{(22)}$. A cultural domain is a collection of items related in the minds of informants, which helps them label, interpret and understand items in their lives. Through these two methods, the food list was built and categorized into ten food groups based on their ingredients and preparation methods: (i) global foods; (ii) snack foods; (iii) non-vegetarian foods; (iv) sweets and desserts; (v) dairy; (vi) beverages; (vii) fruits and seasonal fruits; (viii) vegetables; (ix) traditional foods; and (x) miscellaneous foods. For the eating behaviour section of the NT-FFQ instrument, questions were developed on eating behaviours associated in the literature with the nutrition transition ${ }^{(8,23)}$. The eating behaviours included the adolescent's practice of eating at friends' homes or vice versa, the frequency of eating meals at home $v$. away from home (e.g. at restaurants and at the home of a friend or family member) and the frequency of watching television while eating meals.

\section{Frequency response section of the 125-item NT-FFQ}

The NT-FFQ had eleven frequency categories for food consumption over 1 month, from several times per day to never (see online supplementary material, Table S1). The intake of seasonal fruits was asked over a 3-month period, which is the length of a typical season for most seasonal fruits in India. An additional column beside these frequency categories was included to record whether the participant believed that his or her consumption of each food had increased, decreased or remained the same in the past 6 months. This additional column was tailored from a previous study where participants were asked to 
report if the intake of a food item had greatly increased or decreased during the past 10 years ${ }^{(24)}$. This information was added to the traditional FFQ format to capture dietary changes that may be occurring as part of the nutrition transition.

Frequency response section of the twenty-seven-item eating behaviour section

Of the twenty-seven eating behaviour questions, eighteen questions had the response categories of daily, 4-6 d/week, $1-3 \mathrm{~d} /$ week and never. One question asked participants if they consumed dietary supplements in the past year. The remaining eight questions asked participants about their perceptions of the novelty of eating habits using a 4-point Likert scale with the options 'totally traditional', 'somewhat traditional', 'somewhat modern' and 'totally modern'. These eight questions included the perception of a family with a working mother and the perceptions of eating homecooked food, outside food, eggs, meat and bread, and drinking milk and fruit juice.

\section{NT-FFQ portion size}

We specified a standard serving size for each food (e.g. slices of bread, glass of milk) and included an additional column for participants to report the portion size they consumed if different from the one specified. The standard serving size was determined using those listed in the Dietary Guidelines for Indians ${ }^{(25)}$ and those listed most frequently in our previous 24-HR. Portion size estimates were based on household utensils including cups, spoons and natural units (e.g. small, medium and large size for fruits, etc.). Circular food models were constructed to measure traditional Indian breads including chapati and puri that are typically consumed in varying sizes including small, medium or large (see online supplementary material, Fig. S1). Given that packaged foods including chips, chocolates and popcorn were available in several sizes, participants were asked to report both the quantity consumed over 1 month and the cost of one unit of that item (e.g. cost of 1 bar of chocolate). A database of packaged foods was developed to include the items' cost, weight and nutritional information from the food label. The weight of food in grams was determined according to the cost of the packaged foods and quantity eaten (e.g. 1 bar of chocolate).

\section{Pre-testing the NT-FFQ}

The initial NT-FFQ included 154 items and was rigorously pre-tested using cognitive interviews among a purposive sample of five adolescents aged 14-18 years attending a private school in Vijayapura, India. In the pre-test, adolescents were asked to report their usual intake of foods and beverages over a 3-month period. Using established guidelines $^{(26)}$, the NT-FFQ was tested for content including the clarity of the meaning of food names, portion-size descriptions, unfamiliar food items, length of the instrument and ease of administration. Cognitive interviews have been shown to help identify cognitive problems in dietary questionnaires and improve the accuracy of $\mathrm{FFQ}^{(27,28)}$. We observed that adolescents found it difficult to recall food consumption over a 3-month period and reported that it would be easier to recall food intake over a 1-month period, except for seasonal fruits. In addition, adolescents found twenty-nine items unfamiliar (e.g. tofu). Using this feedback, the NT-FFQ was revised to 125 items with a 1-month reference period. The revised 125-item NT-FFQ was pre-tested again in English and Kannada among a convenience sample of sixteen adolescents of the same age attending a private school and a public school, without encountering additional problems. The NT-FFQ was finalized at 125 items to assess food intake over a 1-month period. On average, it took $35-40 \mathrm{~min}$ to administer the instrument.

\section{Evaluation of the NT-FFQ}

\section{Study population}

The reproducibility and validity of the NT-FFQ were evaluated among 200 adolescents aged 14-18 years. These 200 adolescents were interviewed as a part of the followup of a longitudinal study of 407 adolescents who participated in the 2012 Home Environment and Adolescent Body Weight study in Vijayapura ${ }^{(29)}$. In the 2012 baseline study, a representative stratified random school-based sample of 407 adolescents was drawn from three public and three private schools in Vijayapura.

\section{Design of the evaluation study}

The NT-FFQ was administered during home visits at baseline (NT-FFQ1) and 2 months later (NT-FFQ2) to 200 adolescents. Two adolescents were lost to follow-up during the second administration of NT-FFQ, yielding a final sample of 198 participants. A sub-sample of ninetyseven adolescents completed three additional intervieweradministered 24-HR over the 2-month period as shown in Fig. 1. The interviewers used the multi-pass method for all 24-HR. For each participant, two of the three 24-HR were taken on a weekday and one was taken on the weekend.

\section{Statistical methods}

Data from the NT-FFQ were transformed into daily intake of each food $(\mathrm{g} / \mathrm{d})$ and beverage $(\mathrm{ml} / \mathrm{d})$. The daily intake was calculated by multiplying the specified portion unit by the frequency of intake, using the following values for reported frequencies: more than 3 times $/ \mathrm{d}=3$; twice daily $=2 ;$ once daily $=1 ; 5-6$ times $/$ week $=0 \cdot 79 ; 2-4$ times/week $=0 \cdot 43 ; \quad$ once weekly $=0 \cdot 14 ; \quad 2-3$ times/ month $=0 \cdot 082$; monthly $=0 \cdot 03$; less than once monthly $=$ $0 \cdot 016$; and never eaten or don't know the food $=0$. The 125 foods in the NT-FFQ were collapsed to twenty-one meaningful food groups based on nutrient content as shown in the online supplementary material, Table S2. 


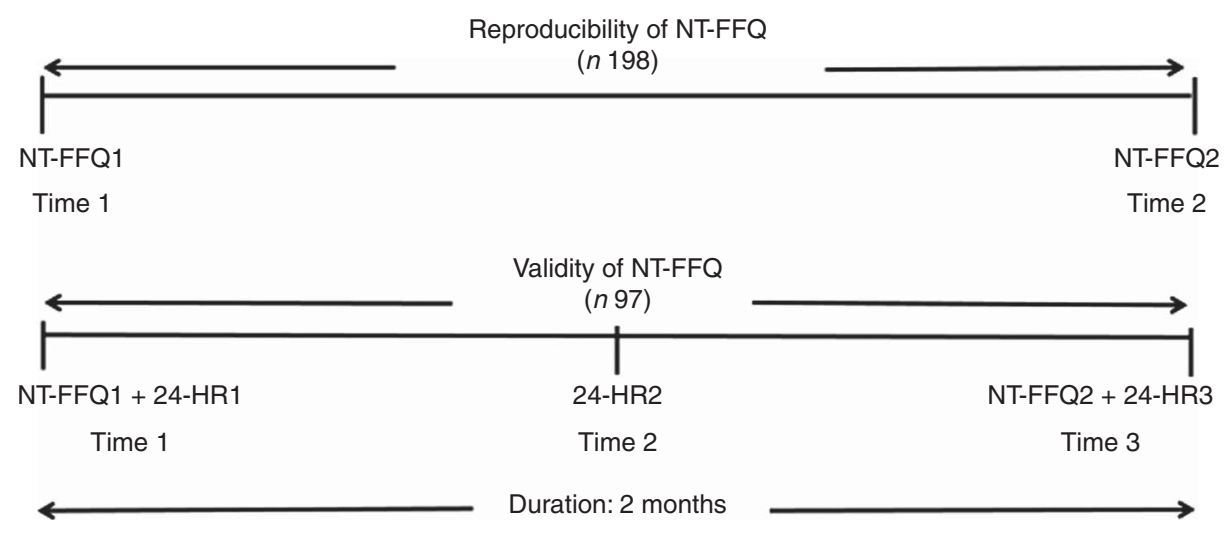

Fig. 1 Design of the reproducibility and validity study to evaluate the Nutrition Transition-FFQ (NT-FFQ) among adolescents in South India. Data were collected in November 2013-January 2014. The NT-FFQ was administered by trained interviewers at homes of 198 adolescents aged 14-18 years at baseline (NT-FFQ1) and after 2 months (NT-FFQ2). A sub-sample of ninety-seven adolescents also completed three interviewer-administered $24 \mathrm{~h}$ dietary recalls $(24-\mathrm{HR})$ during the 2 months between NT-FFQ1 and NT-FFQ2

The reproducibility and validity of the NT-FFQ were assessed using a food-based approach, as done elsewhere ${ }^{(24,30-35)}$.

The reproducibility of the NT-FFQ for foods and food groups was assessed at baseline (NT-FFQ1) and after 2 months (NT-FFQ2) using Spearman and Pearson correlation coefficients, intra-class correlation coefficients (ICC) and cross-classification of food group intakes into tertiles. The measures of agreement or cross-classification were calculated using the percentage of participants in the same (concordance), adjacent and extreme (discordance) tertiles of food intake by both NT-FFQ. The reproducibility of the eating behaviour questions was assessed using weighted kappa $\left(\kappa_{\mathrm{w}}\right)$ statistics and cross-classification analyses.

The validity of the FFQ portion of the NT-FFQ was assessed, in a sub-sample of ninety-seven adolescents, by comparing the intakes of twenty-one food groups from the NT-FFQ2 with the average intakes from the three 24-HR. For each individual in the validation study, the daily intakes of foods consumed during each of the three 24-HR were computed and used to calculate the mean daily intakes of foods and foods groups from the three 24-HR. The mixed dishes from the 24-HR were divided into their components and allocated to the appropriate food items of the questionnaire as would routinely be done in the analysis of mixed dishes ${ }^{(36)}$. Spearman and Pearson correlation coefficients were used to measure the strength of the relationship between food and food group intakes estimated by NT-FFQ2 and the 24-HR. The relative agreement between NT-FFQ2 and the average of the three 24-HR was tested by cross-classification of the food group intakes and estimation of the proportion of participants who were classified by the two methods into the same tertile (concordance) and extreme tertiles (discordance). To assess the 'limits of agreement' between NT-FFQ2 and the average of three 24-HR, the Bland-Altman method was performed for each of the food groups. The differences in intake between the two methods were plotted against the mean intakes of the two instruments for each food group. These estimates were analysed using the statistical software package SAS ${ }^{\circledR}$ version 9.4. $P$ values are two-sided and deemed significant at 0.05.

The face validity of the twenty-seven-item eating behaviour section in the NT-FFQ was evaluated through semi-structured cognitive interviews using paraphrasing and response latency. To evaluate the face validity of the eating behaviour questions, a convenience sample of thirty adolescents aged 14-18 years were selected from one public school and one private school in Vijayapura. Trained interviewers administered the semi-structured cognitive interviews at the home of the participant. To assess paraphrasing, the interviewers elicited a response from the participant and probed for the meaning of each question to ensure consistency with the intent of the question. Response latency was assessed through the time taken to answer each question. In addition, at the end of the interview, the participants were asked if they preferred reporting frequency of eating behaviours over a month instead of over a week.

\section{Results}

\section{Demographic characteristics}

The demographic characteristics of the participants in the NT-FFQ evaluation study are given in Table 1. Of the 198 school-going adolescents eligible for analysis, the mean age was 16.8 years, $55 \%$ were female and $66 \%$ attended public (government-funded) schools.

The intake of each food group based on both administrations of the NT-FFQ and the average intake from the three 24-HR are shown in Table 2. The mean daily intake of most food groups was overestimated by the NT-FFQ when compared with the mean daily intake of food groups estimated from the 24-HR. However, intakes were higher 
when estimated by 24-HR for the fried traditional food group, red meat food group, lean meat food group and sugar food group.

\section{Reproducibility}

Estimates of the reproducibility and validity of the NT-FFQ are given in Table 3. The Spearman correlation coefficients for foods ranged from $0 \cdot 12$ (cooked lentils) to $0 \cdot 80$ (red meat; mean $=0 \cdot 51$ ). For food groups, the Spearman

Table 1 Characteristics of the adolescents $(n 198)$ in the evaluation study of the Nutrition Transition-FFQ (NT-FFQ) in Vijayapura, India†

\begin{tabular}{lcc}
\hline Characteristic & Mean or $n$ & SE or \% \\
\hline Age (years) $¥$ & 16.8 & 0.07 \\
Boy & 108 & 54.5 \\
Public school & 130 & 65.7 \\
Grade in which studying & & \\
X & 25 & 12.6 \\
XI & 97 & 49.0 \\
XII & 24 & 12.1 \\
Short-term or diploma course & 31 & 15.7 \\
School or college dropout & 21 & 10.6 \\
\hline
\end{tabular}

Data were collected in November 2013-January 2014.

†Data are from the second administration of the NT-FFQ (NT-FFQ2).

$\ddagger$ Age presented as mean and its standard error; all other data presented as number and percentage. correlations ranged from 0.33 (pulses and nuts) to 0.80 (red meat; mean $=0.58$ ) and ICC ranged from 0.05 (fruits) to 1.00 (tea and coffee; mean $=0.94$ ). Of the twenty-one food groups, Spearman correlation coefficients were $\geq 0.5$ for sixteen food groups and $\geq 0 \cdot 7$ for five food groups. On average, concordance was $60 \%$ and discordance was $7 \%$. Very good concordance $(\geq 65 \%)$ was determined for lean meat, ghee (clarified butter) and the healthy global food group comprising oats, cereal and multigrain biscuits. The analysis showed good concordance (50-65\%) for the food groups dairy, tea and coffee, red meat, sugar, soda and energy drinks, unhealthy global foods, eggs, fried snacks, grains, fried traditional foods, breads, processed foods, fruit juices, vegetables, snacks, and sweets and desserts; and fair concordance (30-49\%) for the food groups fruits and pulses and nuts. The discordance was less than $10 \%$ for all food groups except for fruit juices (12\%) and snacks (11\%).

For eating behaviours, $\kappa_{\mathrm{w}}$ ranged from $0 \cdot 24$ (eating snacks while watching television) to 0.67 (eating lunch at home) with a mean of $0 \cdot 40$, suggesting moderate agreement (Table 4). On average, the concordance (exact agreement) was 59\% and discordance (opposite agreement) was $1 \%$. Concordance ranged from $42 \%$ (practice of eating sweets prepared outside the home and eating

Table 2 Comparison of food group intakes estimated from the Nutrition Transition-FFQ (NT-FFQ) and the average of the three $24 \mathrm{~h}$ dietary recalls (24-HR) among adolescents in Vijayapura, India

\begin{tabular}{|c|c|c|c|c|c|c|c|c|c|c|c|c|}
\hline \multirow[b]{2}{*}{ Food group } & \multicolumn{4}{|c|}{ NT-FFQ1 $(\mathrm{g} / \mathrm{d}) \ddagger$} & \multicolumn{4}{|c|}{ NT-FFQ2 $(\mathrm{g} / \mathrm{d}) \ddagger$} & \multicolumn{4}{|c|}{ 24-HR $(g / d) \S$} \\
\hline & Mean & SE & Median & IQR $\|$ & Mean & SE & Median & IQR & Mean & SE & Median & IQR \\
\hline \multicolumn{13}{|l|}{ Energy-dense foods } \\
\hline Breads & $31 \cdot 3$ & $2 \cdot 8$ & 14.5 & $4 \cdot 8-45 \cdot 0$ & $30 \cdot 7$ & $2 \cdot 7$ & $14 \cdot 8$ & $4 \cdot 9-44 \cdot 3$ & $9 \cdot 3$ & 1.7 & 0 & $0-16 \cdot 7$ \\
\hline Unhealthy global foods & $25 \cdot 9$ & $2 \cdot 7$ & $12 \cdot 2$ & $4 \cdot 9-31 \cdot 7$ & $27 \cdot 7$ & $2 \cdot 8$ & $12 \cdot 2$ & $4 \cdot 9-31 \cdot 7$ & $5 \cdot 8$ & $2 \cdot 6$ & 0 & 0 \\
\hline Healthy global foods & $1 \cdot 1$ & 0.4 & 0 & 0 & 0.9 & 0.4 & 0 & 0 & 0 & 0 & 0 & 0 \\
\hline Processed foods & 38.9 & $2 \cdot 3$ & $31 \cdot 2$ & $14 \cdot 8-53 \cdot 3$ & 33.3 & $2 \cdot 0$ & 24.9 & $14 \cdot 3-46 \cdot 9$ & $15 \cdot 3$ & $2 \cdot 4$ & $6 \cdot 7$ & $0-20 \cdot 3$ \\
\hline Snacks & 34.9 & $2 \cdot 3$ & $25 \cdot 6$ & $10 \cdot 0-47.5$ & $36 \cdot 4$ & 2.5 & 28.3 & $10 \cdot 9-48.0$ & $16 \cdot 0$ & $2 \cdot 7$ & 0 & $0-20.0$ \\
\hline Fried snacks & $81 \cdot 2$ & $5 \cdot 8$ & $50 \cdot 4$ & $25 \cdot 3-106 \cdot 2$ & 78.9 & 5.5 & 51.4 & $23 \cdot 3-113 \cdot 4$ & $21 \cdot 2$ & 4.0 & 0 & $0-20 \cdot 0$ \\
\hline Fried traditional foods & $23 \cdot 8$ & 1.5 & $16 \cdot 1$ & $9.9-31.8$ & 23.7 & 1.4 & $17 \cdot 2$ & $9.8-31.0$ & 34.5 & 5.5 & 4.0 & $0-50.0$ \\
\hline Sweets and desserts & $55 \cdot 2$ & 3.6 & $38 \cdot 1$ & $20 \cdot 2-71 \cdot 3$ & $51 \cdot 1$ & $3 \cdot 1$ & 39.8 & $19 \cdot 7-64 \cdot 9$ & 19.7 & $2 \cdot 9$ & 0 & $0-38 \cdot 3$ \\
\hline \multicolumn{13}{|l|}{ Animal-source foods } \\
\hline Red meat & 3.0 & 0.5 & 0 & $0-2 \cdot 0$ & $3 \cdot 2$ & 0.5 & 0 & $0-1.6$ & $7 \cdot 1$ & $2 \cdot 3$ & 0 & 0 \\
\hline Lean meat & 9.6 & 1.4 & 0 & $0-12 \cdot 2$ & $9 \cdot 3$ & 1.5 & 1.3 & $0-10.0$ & $11 \cdot 1$ & $3 \cdot 2$ & 0 & 0 \\
\hline Eggs & 19.5 & 1.7 & 9.0 & $2 \cdot 2-26 \cdot 7$ & $17 \cdot 8$ & 1.8 & 8.3 & $1 \cdot 6-25 \cdot 7$ & 7.9 & 1.6 & 0 & $0-16 \cdot 7$ \\
\hline Dairy & $195 \cdot 6$ & $16 \cdot 8$ & $117 \cdot 3$ & $48 \cdot 6-237 \cdot 1$ & $172 \cdot 4$ & $12 \cdot 4$ & $123 \cdot 1$ & $44 \cdot 6-239 \cdot 7$ & 84.0 & $10 \cdot 9$ & $50 \cdot 0$ & $0-116.7$ \\
\hline \multicolumn{13}{|l|}{ Drinks } \\
\hline Soda and energy drinks & $13 \cdot 1$ & 1.8 & $4 \cdot 0$ & $0-16.4$ & $17 \cdot 3$ & $2 \cdot 1$ & 4.0 & $0-20.6$ & 5.5 & $2 \cdot 3$ & 0 & 0 \\
\hline Tea and coffee & $152 \cdot 1$ & 8.3 & 114.0 & $56 \cdot 9-203 \cdot 3$ & 158.4 & $8 \cdot 1$ & $200 \cdot 0$ & $100 \cdot 0-202 \cdot 0$ & $134 \cdot 3$ & $9 \cdot 7$ & $133 \cdot 3$ & $66 \cdot 7-200 \cdot 0$ \\
\hline Fruit juicesף & $27 \cdot 0$ & 2.5 & 13.9 & $6 \cdot 5-34 \cdot 1$ & $29 \cdot 3$ & $2 \cdot 3$ & 18.4 & $7 \cdot 2-37 \cdot 9$ & $7 \cdot 7$ & 2.5 & 0 & 0 \\
\hline \multicolumn{13}{|l|}{ Traditional foods } \\
\hline Fruits & 131.6 & 8.6 & $107 \cdot 8$ & $58.9-160.5$ & $101 \cdot 0$ & 5.6 & $85 \cdot 8$ & $42 \cdot 0-135 \cdot 9$ & $26 \cdot 4$ & 3.7 & 0 & $0-49 \cdot 3$ \\
\hline Vegetables & $128 \cdot 0$ & $6 \cdot 8$ & 103.6 & $60 \cdot 0-169 \cdot 4$ & 114.9 & 7.4 & 88.9 & $52 \cdot 3-144 \cdot 3$ & 79.8 & $7 \cdot 1$ & $61 \cdot 3$ & $33 \cdot 3-103 \cdot 3$ \\
\hline Pulses and nuts & $102 \cdot 2$ & $6 \cdot 1$ & 83.4 & $42 \cdot 2-134 \cdot 5$ & $256 \cdot 0$ & $9 \cdot 9$ & $240 \cdot 6$ & 159.9-337.2 & $159 \cdot 1$ & $9 \cdot 2$ & $155 \cdot 0$ & $96 \cdot 7-208 \cdot 7$ \\
\hline Grains & 588.1 & $19 \cdot 3$ & 537.9 & $490 \cdot 3-548 \cdot 0$ & 550.6 & $18 \cdot 9$ & $507 \cdot 6$ & $481.0-571.9$ & 447.9 & $15 \cdot 5$ & $420 \cdot 3$ & $323 \cdot 3-526 \cdot 0$ \\
\hline Sugar & 3.9 & 0.4 & 0.9 & $0-5.7$ & 4.2 & 0.4 & $1 \cdot 2$ & $0-6.4$ & 8.4 & 4.6 & $8 \cdot 3$ & $5 \cdot 0-10 \cdot 0$ \\
\hline Ghee & 1.4 & 0.2 & 0.1 & $0-1.7$ & 1.2 & 0.2 & 0.1 & $0-1.7$ & 0.9 & 0.2 & 0 & $0-1.3$ \\
\hline
\end{tabular}

NT-FFQ1, first administration of the NT-FFQ; NT-FFQ2, second administration of the NT-FFQ; IQR, interquartile range.

Data were collected in November 2013-January 2014.

†For analysis, the 125 items in the NT-FFQ were reduced to twenty-one meaningful food groups.

$\mp$ A total of 198 adolescents aged 14-18 years were in the reproducibility study.

§A sub-sample of ninety-seven adolescents aged $14-18$ years were in the validity study.

IQR of $25-75 \%$ of the population.

IData presented as $\mathrm{ml} / \mathrm{d}$. 
Table 3 Reproducibility and validity of the Nutrition Transition-FFQ (NT-FFQ) among adolescents in Vijayapura, India

\begin{tabular}{|c|c|c|c|c|c|c|c|c|c|c|c|c|}
\hline \multirow[b]{3}{*}{ Food group $(\mathrm{g} / \mathrm{d})$} & \multicolumn{6}{|c|}{ Reproducibility $\dagger$} & \multicolumn{6}{|c|}{ Validity $\ddagger$} \\
\hline & \multirow{2}{*}{$\begin{array}{l}\text { Pearson } \\
\text { correlation }\end{array}$} & \multirow{2}{*}{$\begin{array}{l}\text { Spearman } \\
\text { correlation }\end{array}$} & \multirow[b]{2}{*}{ ICC } & \multicolumn{3}{|c|}{$\begin{array}{c}\text { Cross-classification by } \\
\text { tertiles }(\%)\end{array}$} & \multirow{2}{*}{$\begin{array}{l}\text { Pearson } \\
\text { correlation }\end{array}$} & \multirow{2}{*}{$\begin{array}{l}\text { Spearman } \\
\text { correlation }\end{array}$} & \multirow[b]{2}{*}{ ICC } & \multicolumn{3}{|c|}{$\begin{array}{c}\text { Cross-classification by } \\
\text { tertiles }(\%)\end{array}$} \\
\hline & & & & Same & Adjacent & Opposite & & & & Same & Adjacent & Opposite \\
\hline \multicolumn{13}{|l|}{ Energy-dense foods } \\
\hline Breads & $0.54^{*}$ & $0.62^{*}$ & 0.99 & $55 \cdot 1$ & $41 \cdot 4$ & 3.5 & $0.65^{* * *}$ & $0.63^{* * *}$ & 0.99 & $56 \cdot 0$ & $35 \cdot 0$ & $9 \cdot 0$ \\
\hline $\begin{array}{l}\text { Unhealthy global } \\
\text { foods }\end{array}$ & $0.50^{*}$ & $0.59^{*}$ & 0.99 & $59 \cdot 0$ & $35 \cdot 0$ & $6 \cdot 0$ & 0.24 & $0 \cdot 24^{*}$ & 0.99 & $40 \cdot 0$ & $54 \cdot 0$ & $6 \cdot 0$ \\
\hline $\begin{array}{l}\text { Healthy global } \\
\text { foods }\end{array}$ & $0.88^{*}$ & $0.60^{*}$ & 0.97 & $90 \cdot 4$ & 0.0 & 9.6 & $-\|$ & $-\|$ & 0.02 & $87 \cdot 0$ & $7 \cdot 8$ & $5 \cdot 2$ \\
\hline Processed foods & $0.55^{\star}$ & $0.56^{*}$ & 0.99 & $55 \cdot 0$ & $37 \cdot 0$ & 8.0 & $0.45^{* * *}$ & $0.47^{* * *}$ & 0.99 & $54 \cdot 0$ & $37 \cdot 0$ & $9 \cdot 0$ \\
\hline Snacks & $0.31^{*}$ & $0.34^{*}$ & 0.99 & 51.0 & 38.0 & 11.0 & 0.21 & $0.23^{*}$ & 0.99 & $40 \cdot 0$ & $49 \cdot 0$ & 11.0 \\
\hline Fried snacks & $0.52^{*}$ & $0.62^{*}$ & 0.99 & 58.0 & $35 \cdot 0$ & $7 \cdot 0$ & $0.26^{\star \star}$ & $0.26^{\star \star}$ & 0.99 & $39 \cdot 0$ & $47 \cdot 0$ & $14 \cdot 0$ \\
\hline $\begin{array}{l}\text { Fried traditional } \\
\text { foods }\end{array}$ & $0.45^{*}$ & $0.54^{*}$ & 0.99 & $57 \cdot 0$ & $35 \cdot 0$ & 8.0 & 0.10 & 0.11 & 0.99 & $37 \cdot 0$ & $49 \cdot 0$ & $14 \cdot 0$ \\
\hline $\begin{array}{l}\text { Sweets and } \\
\text { desserts }\end{array}$ & $0.37^{*}$ & $0.50^{*}$ & 0.99 & $50 \cdot 0$ & $42 \cdot 0$ & 8.0 & 0.17 & 0.17 & 0.99 & $42 \cdot 0$ & $48 \cdot 0$ & $10 \cdot 0$ \\
\hline \multicolumn{13}{|l|}{ Animal-source foods } \\
\hline Red meat & $0.68^{*}$ & $0.80^{*}$ & 0.98 & 61.0 & 0.0 & $9 \cdot 0$ & $0.62^{\star \star \star}$ & $0.43^{\star \star \star}$ & 0.99 & $75 \cdot 3$ & $20 \cdot 0$ & 4.7 \\
\hline Lean meat & $0.34^{*}$ & $0.78^{\star}$ & 0.99 & $75 \cdot 0$ & $21 \cdot 0$ & $5 \cdot 0$ & $0.42^{\star \star \star}$ & $0.24^{\star}$ & 0.99 & $49 \cdot 0$ & $42 \cdot 0$ & $9 \cdot 0$ \\
\hline Eggs & $0.52^{*}$ & $0.72^{*}$ & 0.99 & $58 \cdot 1$ & 38.4 & 3.5 & $0.36^{\star \star \star}$ & $0.47^{\star \star \star}$ & 0.99 & 51.5 & 41.0 & 7.5 \\
\hline Dairy & $0.68^{*}$ & $0.68^{*}$ & 0.99 & 63.0 & $34 \cdot 0$ & 4.0 & $0.68^{\star \star \star}$ & $0.55^{\star \star \star}$ & 0.99 & $42 \cdot 0$ & $51 \cdot 0$ & $7 \cdot 0$ \\
\hline \multicolumn{13}{|l|}{ Drinks } \\
\hline $\begin{array}{l}\text { Soda and energy } \\
\text { drinks§ }\end{array}$ & $0.33^{*}$ & $0.57^{*}$ & 0.99 & $60 \cdot 0$ & $30 \cdot 0$ & $10 \cdot 0$ & 0.22 & $0.25^{\star *}$ & 0.99 & 39.0 & $51 \cdot 0$ & $10 \cdot 0$ \\
\hline Tea and coffee§ & $0.67^{*}$ & $0.73^{*}$ & 1.00 & 61.2 & 33.8 & $5 \cdot 0$ & $0.61^{\star \star \star}$ & $0.70^{\star \star \star}$ & 0.99 & $61 \cdot 0$ & $36 \cdot 0$ & 3.0 \\
\hline Fruit juices§ & $0.46^{\star}$ & $0.48^{*}$ & 0.99 & $52 \cdot 0$ & $36 \cdot 0$ & $12 \cdot 0$ & $0.28^{* *}$ & $0.37^{* *}$ & 0.99 & $43 \cdot 2$ & $47 \cdot 0$ & 9.7 \\
\hline \multicolumn{13}{|l|}{ Traditional foods } \\
\hline Fruits & $0.43^{*}$ & $0.49^{\star}$ & 0.05 & $48 \cdot 0$ & 41.0 & 8.0 & $0.32^{\star *}$ & $0 \cdot 21^{*}$ & 0.99 & $40 \cdot 2$ & $51 \cdot 2$ & 8.6 \\
\hline Vegetables & $0.53^{*}$ & $0.51^{*}$ & 0.99 & 51.0 & 43.0 & 8.0 & $0.37^{\star *}$ & $0.43^{\star \star *}$ & 0.99 & 48.0 & $42 \cdot 0$ & 9.0 \\
\hline Pulses and nuts & $0.30^{*}$ & $0.33^{*}$ & 0.99 & 48.0 & 43.0 & $9 \cdot 0$ & $0.48^{\star \star \star}$ & $0.52^{\star \star \star}$ & 0.99 & 53.6 & $37 \cdot 1$ & $9 \cdot 3$ \\
\hline Grains & $0.52^{*}$ & $0.51^{*}$ & 0.99 & $57 \cdot 0$ & 34.0 & 11.0 & $0.59^{\star \star \star}$ & $0.54^{\star \star \star}$ & 1.00 & $55 \cdot 0$ & $35 \cdot 0$ & $10 \cdot 0$ \\
\hline Sugar & $0.48^{*}$ & $0.50^{*}$ & 0.97 & $60 \cdot 1$ & 31.3 & 8.1 & $0.35^{\star *}$ & $0.23^{*}$ & 0.95 & $27 \cdot 0$ & 67.0 & 6.0 \\
\hline Ghee & $0.38^{*}$ & $0.69^{*}$ & 0.86 & 68.2 & $27 \cdot 8$ & 4.0 & $0.47^{\star \star \star}$ & $0.43^{\star \star *}$ & 0.72 & 57.7 & $36 \cdot 1$ & $6 \cdot 2$ \\
\hline
\end{tabular}

ICC, intra-class correlation coefficient.

Data were collected in November 2013-January 2014.

${ }^{\star} P<0.05,{ }^{\star *} P<0.01,{ }^{\star \star \star} P<0.001$.

†Reproducibility of the NT-FFQ is the comparison of NT-FFQ1 (first administration of the NT-FFQ) $v$. NT-FFQ2 (second administration of the NT-FFQ). There were 198 adolescents aged $14-18$ years in the reproducibility study.

$\mp$ Validity of the NT-FFQ is the comparison of NT-FFQ2 $v$. the average of the three $24 \mathrm{~h}$ dietary recalls $(24-\mathrm{HR})$. A sub-sample of ninety-seven adolescents were in the validity study.

$\S$ Data presented as $\mathrm{ml} / \mathrm{d}$.

$\|$ Spearman and Pearson correlations cannot be computed as there is no reported intake of the global healthy foods in the three $24-\mathrm{HR}$.

sweets prepared at home) to $94 \%$ (practice of eating dinner at home). Discordance was $\leq 4 \%$ for twenty-four of the twenty-seven eating behaviour questions. A maximum discordance of $5 \%$ was found for the practice of eating breakfast outside home and for the perception question, from totally traditional to totally modern, of a family with a working mother.

\section{Validity}

For the 125-item NT-FFQ, Spearman correlation coefficients for foods ranged from $0 \cdot 14$ (buns) to 0.79 (chocolate milk powder; mean $=0.39$ ) and for food groups ranged from $0 \cdot 11$ (fried traditional foods) to 0.70 (tea or coffee; mean $=0 \cdot 37$ ). The ICC for food groups ranged from 0.02 (healthy global foods) to 1.00 (grains; mean $=0.93$ ). Of the twenty-one food groups, Spearman correlation coefficients were $\geq 0.5$ for five food groups and $\geq 0 \cdot 3$ for eleven food groups. Comparing the intakes of food groups between the NT-FFQ and the 24-HR, concordance was $49 \%$ and discordance was $8 \%$. The agreement analysis revealed very good concordance ( $\geq 65 \%$ ) for the red meat and healthy global food groups; good concordance (50-65\%) for the food groups tea and coffee, ghee, breads, grains, pulses and nuts, processed foods and eggs; fair concordance (30-49\%) for vegetables, fruit juices, sweets and desserts, dairy, unhealthy global foods, snacks, fruits, fried snacks, soda and energy drinks, and fried traditional foods; and low concordance (27\%) for sugar. The discordance was less than $10 \%$ for all food groups except for the fried snacks (14\%) and fried traditional foods (14\%). The Bland-Altman plots showed acceptable agreement for food groups between the NT-FFQ2 and the 24-HR as shown in Fig. 2.

The twenty-seven-item eating behaviour questions in the NT-FFQ were found to have acceptable face validity. 
Table 4 Reproducibility of the twenty-seven eating behaviour questions in the Nutrition Transition-FFQ for adolescents in Vijayapura, India

\begin{tabular}{|c|c|c|c|}
\hline \multirow[b]{2}{*}{ Eating behaviour $\dagger$} & \multirow[b]{2}{*}{$\kappa_{\mathrm{w}}$} & \multicolumn{2}{|c|}{ Cross-classification (\%)‡ } \\
\hline & & Concordance & Discordance \\
\hline Eating with friends at home & 0.32 & 57 & 0 \\
\hline Eating outside food with friends & 0.41 & 48 & 0 \\
\hline Eating outside food brought home & 0.37 & 46 & 0 \\
\hline $\begin{array}{l}\text { Eating Indian sweets made outside } \\
\text { home }\end{array}$ & 0.29 & 42 & 1 \\
\hline Eating Indian sweets made at home & 0.29 & 42 & 0 \\
\hline Eating fried foods made at home & 0.30 & 46 & 1 \\
\hline \multicolumn{4}{|l|}{ At home } \\
\hline Eating breakfast & 0.50 & 71 & 1 \\
\hline Eating lunch & 0.67 & 78 & 1 \\
\hline Eating evening snack & 0.40 & 52 & 3 \\
\hline Eating dinner & 0.35 & 94 & 1 \\
\hline \multicolumn{4}{|l|}{ Outside home } \\
\hline Eating breakfast & 0.49 & 60 & 5 \\
\hline Eating lunch & 0.60 & 70 & 2 \\
\hline Eating evening snack & 0.37 & 58 & 1 \\
\hline Eating dinner & 0.38 & 83 & 3 \\
\hline \multicolumn{4}{|l|}{ Watching television } \\
\hline While eating breakfast & 0.39 & 70 & 0 \\
\hline While eating lunch & 0.41 & 74 & 0 \\
\hline While eating evening snack & 0.24 & 63 & 3 \\
\hline While eating dinner & 0.41 & 78 & 0 \\
\hline \multicolumn{4}{|l|}{ Eating habits } \\
\hline \multicolumn{4}{|l|}{ Traditional or modern§ } \\
\hline Eating home cooked food & 0.37 & 49 & 3 \\
\hline Eating outside food & 0.25 & 57 & 0 \\
\hline Eating eggs & 0.34 & 46 & 4 \\
\hline Eating meat & 0.41 & 48 & 3 \\
\hline Eating bread & 0.28 & 52 & 1 \\
\hline Drinking milk & 0.40 & 52 & 4 \\
\hline Drinking fruit juice & 0.39 & 55 & 1 \\
\hline Family with working mother & 0.42 & 50 & 5 \\
\hline Mean & 0.40 & 59 & 1 \\
\hline
\end{tabular}

$\kappa_{\mathrm{w}}$, weighted kappa.

Data were collected in November 2013-January 2014.

†A total of 198 adolescents aged $14-18$ years were in the reproducibility study.

¥Cross-classification: concordance (exact agreement) and discordance (opposite agreement).

§Perceptions of the novelty of eating habits were asked using a 4-point Likert scale with the options 'totally traditional', 'somewhat traditional', 'somewhat modern' and 'totally modern'.

Through the assessment of paraphrasing, participants were found to be able to understand, explain and repeat the questions in their own words. Additionally, all participants reported that it was easier to report eating behaviours over a week as opposed to over a month.

\section{Discussion}

Changing dietary patterns from the ongoing nutrition transition among adolescents in India have drawn attention to the lack of validated dietary instruments to assess the nutrition transition among this population. To address this gap, we followed a sequenced mixed-methods approach to develop and to evaluate a dietary instrument, the NT-FFQ, which can be used to assess the nutrition transition among adolescents in South India. This NT-FFQ provides reasonably reproducible and valid estimates for most foods, food groups and eating behaviours in India. To our knowledge, it is the first validated FFQ for adolescents in India and the first validated dietary instrument to assess nutrition transition-related food consumption and eating behaviours.

As seen in other studies among adults ${ }^{(31,36-38)}$ and adolescents $^{(39,40)}$, the FFQ overestimated intakes relative to the reference method for most food groups. In Western settings, correlations in the range of $0.5-0 \cdot 7$ for food intakes are considered acceptable ${ }^{(41)}$. The direct comparison of our study with similar FFQ evaluation studies is complicated by the fact that the food groups chosen were not similar across studies. Reference instruments also differed between studies $^{(24,33)}$. To the extent that comparisons can be made for evaluating the reproducibility of FFQ for individual foods and food groups, Spearman correlation coefficients for our study are comparable to those described for other studies $^{(24,31,34,42)}$. In our study, Spearman correlation coefficients were $\geq 0.7$ for five food groups and $\geq 0.5$ for the remaining sixteen of twenty-one food groups, suggesting that the reproducibility of the NT-FFQ was good. The Spearman correlation coefficients for the reproducibility of the NT-FFQ tended to be higher $(\geq 0.65)$ for commonly consumed foods than for infrequently consumed foods $(<0 \cdot 30)$, as reported elsewhere ${ }^{(43)}$. Salvini et al. reported Pearson correlation coefficients $>0.70$ for $23 \%$ of the foods and $>0.50$ for $73 \%$ of the foods on a fifty-five-item self-administered FFQ completed 6 months apart among 173 women in the Nurses' Health Study ${ }^{(24)}$. Even though Pearson correlation coefficients were reported, these were found to be very similar to the Spearman correlation coefficients ${ }^{(24)}$. Another study among 1497 women that compared two Nurses' Health Study FFQ (1979 FFQ version $v$. 1980 FFQ version) found that Spearman correlation coefficients ranged between 0.34 (readymade pie) and 0.76 (tea) ${ }^{(42)}$. In a third study, high reproducibility using Spearman correlations $(r \geq 0 \cdot 7)$ was reported for half of the food groups and moderate reproducibility $(r<0 \cdot 7)$ was reported for the other half of the food groups ${ }^{(31)}$. The validation study was carried out among 104 German adults aged 35-64 years who completed a 158-item FFQ administered at two intervals, 6 months apart, and 24-HR at monthly intervals ${ }^{(31)}$. Ocke et al. reported Spearman correlations for foods and food groups in the range from 0.45 to 0.92 (median $r=0.7$ ) on a 178-item self-administered FFQ completed thrice during 6-month intervals among 121 adults $^{(34)}$.

In our study, discordance (extreme tertiles) between the intakes in NT-FFQ1 and NT-FFQ2 was <10\% (range: $3 \cdot 5-12 \%)$ for most foods groups except for fruit juices (12\%) and snacks (11\%). Fruit intakes had a low ICC of 0.05 with $8 \%$ being misclassified. In an FFQ validation study among ninety-nine participants interviewed within 1.5 years, the concordance (exact agreement) ranged from $57 \%$ (coleslaw) to $98 \%$ (vodka) ${ }^{(44)}$. In another study where an FFQ was administered to sixty-three participants at the beginning and the end of 3 months, the concordance (same or adjacent category) was $90 \%{ }^{(45)}$. 
(a)

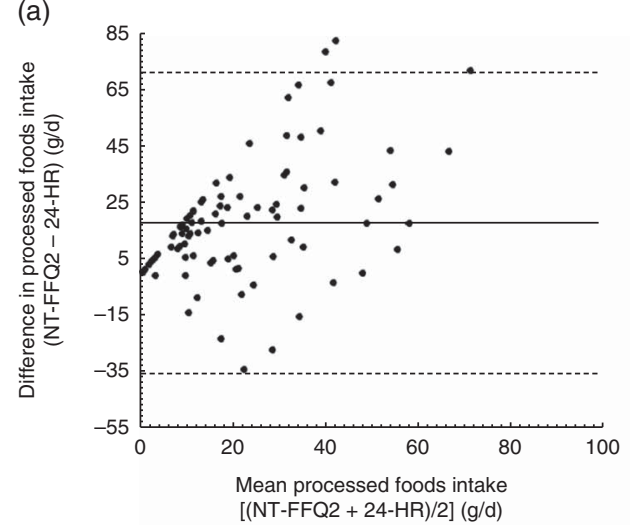

(c)

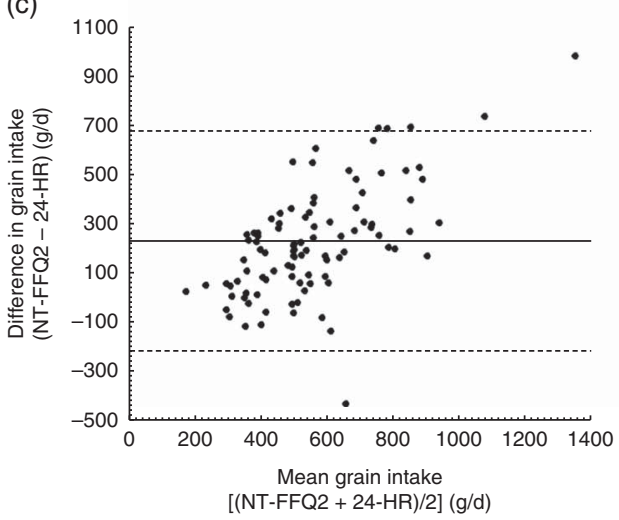

(b)

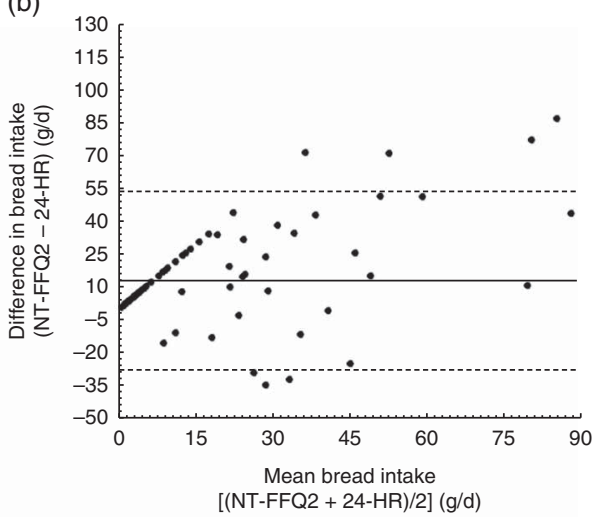

(d)

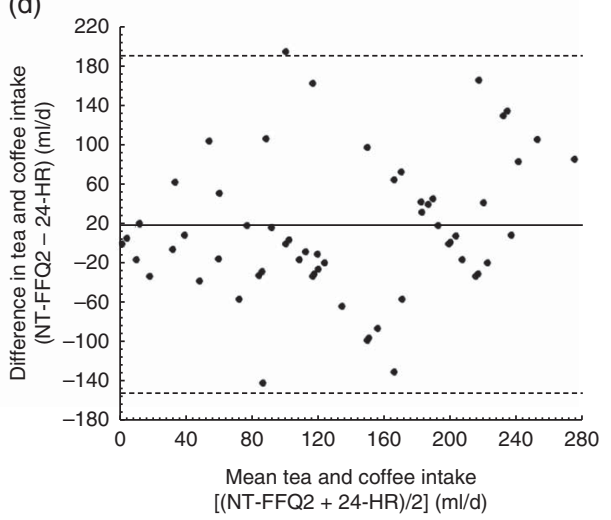

Fig. 2 Bland-Altman plots assessing the relative validity of the Nutrition Transition-FFQ (NT-FFQ) among adolescents ( $n$ 97) in Vijayapura, India, data collected in November 2013-January 2014. The difference in intake between the second administration of the NT-FFQ (NT-FFQ2) and the average of the three $24 \mathrm{~h}$ dietary recalls $(24-\mathrm{HR})$ is plotted $v$. the mean intake from the two methods for: (a) processed foods, (b) breads, (c) grains and (d) tea and coffee. $—$ represents the mean difference (bias) and - - - - represent the limits of agreement $( \pm 2 \mathrm{SD})$

The validity of the NT-FFQ to measure nutrition transition was assessed against the 24-HR. In the validation of FFQ, mean correlation coefficients of 0.40 are indicative of good validity between the FFQ and the reference methods ${ }^{(46)}$, whereas correlations in the range of $0.50-0.70$ are desired between the study and reference methods ${ }^{(41)}$. In the present study, the mean Spearman correlation coefficient was 0.37 with the correlations $\geq 0.40$ for seventeen of the twenty-one food groups, indicating fair agreement. Other FFQ studies, validated for foods and foods groups, have reported correlation coefficients ranging from 0.3 to $0 \cdot 8^{(24,31,33,35)}$. In the validation of a 158-item FFQ among middle-aged German adults, Spearman correlations for foods and food groups between FFQ2 and 24-HR showed values between 0.14 and 0.90 , with most between 0.4 and $0 \cdot 6^{(31)}$. Four food groups yielded correlations $>0 \cdot 6$, eleven groups showed values between 0.4 and 0.6 , and the remaining nine food groups yielded correlations $<0 \cdot 4^{(31)}$. In another study that validated a fifty-three-item FFQ among German adults aged 18-80 years, Spearman rank correlations between the FFQ and two 24-HR ranged from $0 \cdot 15$ (pizza) to 0.80 (tea), with two-thirds of the Spearman correlations $>0 \cdot 30^{(35)}$.
The cross-classification of intakes (concordance and discordance) reported in NT-FFQ2 and the three 24-HR in our study is similar to that reported in other studies ${ }^{(31,33,36)}$. In a study that evaluated food group intakes from an FFQ against a $3 \mathrm{~d}$ diet record among Flemish children, the concordance (same or adjacent category) was 67\% (meat products) to $88 \%$ (fruit juices) and discordance (opposite category) was $<10 \%$ for all food groups ${ }^{(33)}$. In the paper by Bohlscheid-Thomas et al., the concordance (exact quintile) ranged from $21.2 \%$ for legumes to $59.6 \%$ for alcoholic drinks, with most values lying between 30 and $40 \%$, and discordance (extreme quintile) was $<4.8 \%{ }^{(31)}$. As reported by Haftenberger et al., the concordance (same or adjacent quartile) ranged between 68\% (cooked vegetables) and $94 \%$ (coffee $)^{(35)}$. Similar to our study, other studies reported that discordance was $<10 \%$ for most food groups ${ }^{(35,36)}$. The low concordance between NT-FFQ1 and NT-FFQ2 for lentils and pulses may stem from the large number of foods in the group, some that are eaten more frequently than others; which may make it challenging to estimate the average monthly intake. For instance, in Indian households, pigeon pea (tur dal) is typically consumed more frequently than kidney beans (rajma). 
Bland-Altman plots were generated to visually examine the agreement between the NT-FFQ and 24-HR across the range of intake of food groups. The Bland-Altman method also allows one to identify bias between the administration of the questionnaires and to see the nature of the bias across the range of intakes ${ }^{(47)}$. As given in Fig. 2, the Bland-Altman plots of food groups demonstrated good agreement between the NT-FFQ and 24-HR. For all food groups, fewer than $10 \%$ of the participants were outside the limits of agreement.

The present study has certain limitations that need to be taken into account. First, dietary assessment of children has been shown to have methodological problems relating to their limited knowledge of foods, difficulty in the estimation of frequency of consumed foods and potential response bias $^{(48-50)}$. As participants were interviewed at home often in the presence of one or more family members, a potential response bias may have resulted. However, the reliability of dietary recalls from 14-18-year-olds should not be a concern as numerous studies have reported that by age 8-10 years, children can report their food intake as reliably as their parents ${ }^{(49,51,52)}$. Second, the 125 -item NT-FFQ took $35-40 \mathrm{~min}$ to complete and might be considered lengthy, but a response rate of $99 \%$ shows that participants were motivated to participate in the study. The length of the NTFFQ also falls within the acceptable 130-item limit at which adolescents have been found willing to complete long questionnaires $^{(41)}$. Third, the sources of error in FFQ have been reported as due to the restriction imposed by a fixed list of foods, seasonal and regional variations in the availability of foods, memory, perception of portion sizes and interpretation of questions ${ }^{(41)}$. However, given the vast variety of foods and beverages and their variations across India, the NT-FFQ was developed to capture the salient intakes of global, national and regional items as relevant to adolescents in South India. We expect minimum error in the measurement of seasonal foods, given that the NT-FFQ and 24-HR were administered within the same winter season (November-January), and expect minimum error in the measurement of seasonal fruits as their intake was recorded over the length of a typical season. Across the three recorded 24-HR, participants did not consume twenty-nine of 125 foods listed on the NT-FFQ. Of the twenty-nine foods, seven were seasonal foods that were not typically consumed during the period of the validation study and the remaining foods were infrequently consumed (once monthly or less) by adolescents. These twenty-nine foods were likely to be consumed at festivals, in summer or may be relatively new to this region. Fourth, the low ICC ( 0.02$)$ for the intake of healthy global foods between the NTFFQ2 and 24-HR may be attributed to their infrequent intake $(0.3 \mathrm{~g} / \mathrm{d}$ or less than once monthly). The healthy global food group includes oats, breakfast cereals and multigrain biscuits, which are not commonly consumed by adolescents in our study. However, some infrequently consumed foods were included in the NT-FFQ to capture foods that may be relatively new to this region but may soon become a part of the local food environment. This phenomenon is corroborated in a similar study that reported low probability of eating rarely consumed foods ${ }^{(35,36)}$. In order to validate the intake of infrequently consumed foods with better accuracy we would require large calibration studies, as reported elsewhere ${ }^{(32)}$. The documentation of the increasing availability of global, national and regional foods not only in urban regions but also in remote, but urbanizing regions is a large part of our work. Further research could explore how adolescents' access to and selection of foods may be influenced by the food marketplace in India.

The present study offers several strengths. First, the estimates of reproducibility and validity of the foods in the NT-FFQ were evaluated with a comprehensive range of tests, including correlations coefficients and crossclassification in conjunction with the Bland-Altman method. The Bland-Altman method has been preferred over correlation analysis as a method to evaluate the reproducibility and validity of an $\mathrm{FFQ}^{(53)}$. Furthermore, the sample size of the present study was large enough to allow for the estimation of the limits of agreement from the Bland-Altman analysis as a component of the evaluation of the validity of the NT-FFQ. Second, the reproducibility of the eating behaviour questions was assessed using cross-classification and $\kappa_{\mathrm{w}}$. The use of semi-structured cognitive interviews strengthened the validation of the eating behaviour questions. Third, the validated NT-FFQ can serve as a useful instrument in ranking adolescents according to both food intake and eating behaviours, and can be used in epidemiological research. Lastly, the acceptable measures of agreement between the NT-FFQ and 24-HR may be a result of the NT-FFQ's flexibility wherein participants were able to describe a portion size if they did not find a suitable portion size on the questionnaire. This method, where participants are able to describe their own portion size, has been found to provide the highest estimates of correlation coefficients $(0.5-0.6)$ compared with the method where portion size is specified on the questionnaire (correlation coefficients $=0.4-0.5$ ) or when no portion size is specified but the average portion weights are used to compute intakes (correlation coefficients $=0 \cdot 2-0 \cdot 5)^{(53)}$.

\section{Conclusion}

Globalization and nutrition transition in India have drawn attention to the lack of existing validated dietary instruments to assess the food consumption and eating behaviours of adolescents. To address this gap, we developed and evaluated an NT-FFQ for adolescents; this NT-FFQ has good reproducibility and acceptable validity for most food groups and eating behaviours. The NT-FFQ can be used in epidemiological studies to assess food intakes and eating behaviours associated with the nutrition transition among 
adolescents in South India. Our team is evaluating the NTFFQ among adolescents residing in an urban region in South India. The development of the NT-FFQ represents an important and much needed first step that allows us to measure dietary changes and eating behaviours among adolescents in a globalizing society.

\section{Acknowledgements}

Acknowledgements: The authors would like to thank Dr Veena Algur at BLDE University for her assistance with translation from English to Kannada and Dr Rob O'Reilly at the Emory Center for Digital Scholarship for his assistance with data merging. The authors would like to thank the field research team and the adolescents for their participation in this study. Financial support: This work was supported by the Eunice Kennedy Shriver National Institute of Child Health and Human Development (NICHD; grant number 3D43HD065249-03S1). N.I.S. was supported by the National Institutes of Health (NIH; grant number 1 R25 TW009337-01) funded by the Fogarty International Center and the 2013 Amy Joye Memorial Research Award from the Academy of Nutrition and Dietetics Foundation. Disclosure: This work is solely the responsibility of the authors and does not necessarily represent the official views of the Fogarty International Center, NIH or the Academy of Nutrition and Dietetics Foundation. The Fogarty International Center, NIH and the Academy of Nutrition and Dietetics Foundation had no role in the design, analysis or writing of this article. Conflict of interest: None. Authorship: N.I.S. and S.A.C. formulated the research question; N.I.S., J.K.F., U.R. and S.A.C. designed the study; N.I.S. and S.S.P. carried it out; N.I.S. analysed the data, with interpretative input from all authors; N.I.S. drafted the manuscript; all authors helped to revise the manuscript and approved the final version. Ethics of human subject participation: The Institutional Review Board at Emory University, Atlanta, GA, USA and the Institutional Ethical Committee at BLDE University, Vijayapura, India approved the study.

\section{Supplementary material}

To view supplementary material for this article, please visit http://dx.doi.org/10.1017/S1368980016003335

\section{References}

1. Popkin BM, Horton S, Kim S et al. (2001) Trends in diet, nutritional status, and diet-related noncommunicable diseases in China and India: the economic costs of the nutrition transition. Nutr Rev 59, 379-390.

2. Popkin BM (1994) The nutrition transition in low-income countries: an emerging crisis. Nutr Rev 52, 285-298.

3. Drewnowski A \& Popkin BM (1997) The nutrition transition: new trends in the global diet. Nutr Rev 55, 31-43.
4. Satia JA (2010) Dietary acculturation and the nutrition transition: an overview. Appl Physiol Nutr Metab 35, 219-223.

5. Popkin BM \& Gordon-Larsen P (2004) The nutrition transition: worldwide obesity dynamics and their determinants. Int J Obes Relat Metab Disord 28, Suppl. 3, S2-S9.

6. Zingoni C, Norris SA, Griffiths PL et al. (2009) Studying a population undergoing nutrition transition: a practical case study of dietary assessment in urban South African adolescents. Ecol Food Nutr 48, 178-198.

7. Singhal S, Goyle A \& Gupta R (1998) Quantitative food frequency questionnaire and assessment of dietary intake. Natl Med J India 11, 268-275.

8. Adair LS \& Popkin BM (2005) Are child eating patterns being transformed globally? Obes Res 13, 1281-1299.

9. Kuriyan R, Bhat S, Thomas T et al. (2007) Television viewing and sleep are associated with overweight among urban and semi-urban South Indian children. Nutr J 6, 25 .

10. Dasen P (2000) Rapid social change and the turmoil of adolescence: a cross-cultural perspective. Int J Group Tensions 29, 17-49.

11. UNICEF (2011) The State of the World's Children 2011. Adolescence: An Age of Opportunity. New York: UNICEF.

12. Patel SA, Narayan KM \& Cunningham SA (2015) Unhealthy weight among children and adults in India: urbanicity and the crossover in underweight and overweight. Ann Epidemiol 25, 336-341.e2.

13. Swaminathan S, Thomas T, Kurpad AV et al. (2007) Dietary patterns in urban school children in South India. Indian Pediatr 44, 593-596.

14. Vijayapushpam T, Menon KK, Raghunatha Rao D et al. (2003) A qualitative assessment of nutrition knowledge levels and dietary intake of schoolchildren in Hyderabad. Public Health Nutr 6, 683-688.

15. Raghunatha Rao D, Antony GM, Sarma KVR et al. (2007) Dietary habits and effect of two different educational tools on nutrition knowledge of school going adolescent girls in Hyderabad, India. Eur J Clin Nutr 61, 1081-1085.

16. National Institute of Nutrition (2000) Diet and nutritional status of adolescents. In National Nutrition Monitoring Bureau, Special Report. NNMB Technical Report no. 20, pp. 1-25. Hyderabad: NIN.

17. Rockett HR, Berkey CS \& Colditz GA (2003) Evaluation of dietary assessment instruments in adolescents. Curr Opin Clin Nutr Metab Care 6, 557-562.

18. Slater B, Enes CC, Lopez RV et al. (2010) Validation of a food frequency questionnaire to assess the consumption of carotenoids, fruits and vegetables among adolescents: the method of triads. Cad Saude Publica 26, 2090-2100.

19. Jayawardena R, Swaminathan S, Byrne NM et al. (2012) Development of a food frequency questionnaire for Sri Lankan adults. Nutr J 11, 63.

20. Government of India, Ministry of Micro Small and Medium Enterprises (2011) Brief Industrial Profile of Bijapur District. Bijapur: Government of Karnataka.

21. Shaikh NI, Patil SS, Halli S et al. (2016) Going global: Indian adolescents' eating patterns. Public Health Nutr 19, 2799-2807.

22. Borgatti S (1999) Elicitation techniques for cultural domain analysis. In Ethnographer's Toolkit. vol. 3: Enhanced Ethnographic Methods: Audiovisual Techniques, Focused Group Interviews, and Elicitation Techniques, pp. 115-151 [JJ Schensul, MD LeCompte, BK Natasi et al., editors]. Walnut Creek, CA: AltaMira.

23. Wang Z, Zhai F, Du S et al. (2008) Dynamic shifts in Chinese eating behaviors. Asia Pac J Clin Nutr 17, 123-130.

24. Salvini S, Hunter DJ, Sampson L et al. (1989) Foodbased validation of a dietary questionnaire: the effects of 
week-to-week variation in food consumption. Int J Epidemiol 18, 858-867.

25. National Insitute of Nutrition, Indian Council of Medical Research (2011) Dietary Guildelines for Indians, 2011 edition. Hyderabad: NIN.

26. Cade JE, Burley VJ, Warm DL et al. (2004) Food-frequency questionnaires: a review of their design, validation and utilisation. Nutr Res Rev 17, 5-22.

27. Subar AF, Thompson FE, Smith AF et al. (1995) Improving food frequency questionnaires: a qualitative approach using cognitive interviewing. J Am Diet Assoc 95, 781-788.

28. Thompson FE, Subar AF, Brown CC et al. (2002) Cognitive research enhances accuracy of food frequency questionnaire reports: results of an experimental validation study. J Am Diet Assoc 102, 212-225.

29. Staab EM, Cunningham SA, Thorpe S et al. (2006) A 'snapshot' of nutrition and physical activity among private school adolescents in rural India. Childhood 23, 537-553.

30. Millen AE, Midthune D, Thompson FE et al. (2006) The National Cancer Institute diet history questionnaire: validation of pyramid food servings. Am J Epidemiol 163, 279-288.

31. Bohlscheid-Thomas S, Hoting I, Boeing H et al. (1997) Reproducibility and relative validity of food group intake in a food frequency questionnaire developed for the German part of the EPIC project. European Prospective Investigation into Cancer and Nutrition. Int J Epidemiol 26, Suppl. 1, S59-S70.

32. Midthune D, Schatzkin A, Subar AF et al. (2011) Validating an FFQ for intake of episodically consumed foods: application to the National Institutes of Health-AARP Diet and Health Study. Public Health Nutr 14, 1212-1221.

33. Huybrechts I, De Backer G, De Bacquer D et al. (2009) Relative validity and reproducibility of a food-frequency questionnaire for estimating food intakes among Flemish preschoolers. Int J Environ Res Public Health 6, 382-399.

34. Ocke MC, Bueno-de-Mesquita HB, Goddijn HE et al. (1997) The Dutch EPIC food frequency questionnaire. I. Description of the questionnaire, and relative validity and reproducibility for food groups. Int J Epidemiol 26, Suppl. 1, S37-S48.

35. Haftenberger M, Heuer T, Heidemann C et al. (2010) Relative validation of a food frequency questionnaire for national health and nutrition monitoring. Nutr J9, 36.

36. Zhuang M, Yuan Z, Lin L et al. (2012) Reproducibility and relative validity of a food frequency questionnaire developed for adults in Taizhou, China. PLoS One 7, e48341.

37. Bowen L, Bharathi AV, Kinra S et al. (2012) Development and evaluation of a semi-quantitative food frequency questionnaire for use in urban and rural India. Asia Pac J Clin Nutr 21, 355-360.
38. Mahajan R, Malik M, Bharathi AV et al. (2013) Reproducibility and validity of a quantitative food frequency questionnaire in an urban and rural area of northern India. Natl Med J India 26, 266-272.

39. Araujo MC, Yokoo EM \& Pereira RA (2010) Validation and calibration of a semiquantitative food frequency questionnaire designed for adolescents. J Am Diet Assoc 110, 1170-1177.

40. Tabacchi G, Filippi AR, Breda J et al. (2015) Comparative validity of the ASSO-Food Frequency Questionnaire for the web-based assessment of food and nutrients intake in adolescents. Food Nutr Res 59, 26216.

41. Willett W (2013) Nutritional Epidemiology, 3rd ed. Oxford: Oxford University Press.

42. Colditz GA, Willett WC, Stampfer MJ et al. (1987) The influence of age, relative weight, smoking, and alcohol intake on the reproducibility of a dietary questionnaire. Int J Epidemiol 16, 392-398.

43. Wiecha JM, Hebert JR \& Lim M (1994) Diet measurement in Vietnamese youth: concurrent reliability of a selfadministered food frequency questionnaire. J Community Health 19, 181-188.

44. Graham S, Lilienfeld AM \& Tidings JE (1967) Dietary and purgation factors in the epidemiology of gastric cancer. Cancer 20, 2224-2234.

45. Acheson ED \& Doll R (1964) Dietary factors in carcinoma of the stomach: a study of 100 cases and 200 controls. Gut $\mathbf{5}$, 126-131.

46. Samaras K, Kelly PJ, Chiano MN et al. (1998) Genes versus environment. The relationship between dietary fat and total and central abdominal fat. Diabetes Care 21, 2069-2076.

47. Bland JM \& Altman DG (1986) Statistical methods for assessing agreement between two methods of clinical measurement. Lancet 1, 307-310.

48. Rockett HR, Breitenbach M, Frazier AL et al. (1997) Validation of a youth/adolescent food frequency questionnaire. Prev Med 26, 808-816.

49. Livingstone MB, Robson PJ \& Wallace JM (2004) Issues in dietary intake assessment of children and adolescents. $\mathrm{BrJ}$ Nutr 92, Suppl. 2, S213-S222.

50. Hebert JR, Gupta PC, Bhonsle RB et al. (2002) Dietary exposures and oral precancerous lesions in Srikakulam District, Andhra Pradesh, India. Public Health Nutr 5, 303-312.

51. Emmons L \& Hayes M (1973) Accuracy of 24-hr. recalls of young children. J Am Diet Assoc 62, 409-415.

52. Jenner DA, Neylon K, Croft S et al. (1989) A comparison of methods of dietary assessment in Australian children aged 11-12 years. Eur J Clin Nutr 43, 663-673.

53. Cade J, Thompson R, Burley V et al. (2002) Development, validation and utilisation of food-frequency questionnaires a review. Public Health Nutr 5, 567-587. 